Editorial

\title{
Big Data Research for Social Science and Social Impact
}

\author{
Miltiadis D. Lytras ${ }^{1,2, *(1)}$ and Anna Visvizi ${ }^{1,3}$ (I) \\ 1 School of Business and Economics, Deree College-The American College of Greece, 153-42 Athens, Greece; \\ avisvizi@acg.edu \\ 2 Effat College of Engineering, Effat University, Jeddah P.O. Box 34689, Saudi Arabia \\ 3 Effat College of Business, Effat University, Jeddah P.O. Box 34689, Saudi Arabia \\ * Correspondence: mlytras@acg.edu; Tel.: +30-210-600-9800
}

Received: 13 December 2019; Accepted: 14 December 2019; Published: 24 December 2019

check for updates

\begin{abstract}
This Special Issue of Sustainability devoted to the topic of "Big Data Research for Social Sciences and Social Impact" attracted significant attention of scholars, practitioners, and policy-makers from all over the world. Locating themselves at the cross-section of advanced information systems and computer science research and insights from social science and engineering, all papers included in this Special Issue contribute to the debate on the use of big data in social sciences and big data social impact. By promoting a debate on the multifaceted challenges that our societies are exposed to today, this Special Issue offers an in-depth, integrative, well-organized, comparative study into the most recent developments shaping the future directions of interdisciplinary research and policymaking.
\end{abstract}

Keywords: big data research; social and humanistic computing; social sciences; social good; social impact; machine learning; knowledge management; web science; data science; social inclusive economic growth; sustainability; innovation; innovation networks

\section{Introduction-Overview of the Edited Volume}

The evolution of big data research and social media and the contributions of individuals and organizations in social networking data ecosystems resulted in a new, sophisticated context for technology-facilitated social interactions [1]. In parallel, a number of social challenges and problems, and the critical need to enhance the capability of our society to deal with delicate social issues, sets new directions for research [2]. The focus of this edited volume is on the intersection of advanced information systems and social sciences research [3,4]. It is about analyzing the impact of data and their processing to the understanding and addressing of significant social problems. It is also about analyzing data as a social good that must be protected and be aligned with significant rules and ethical principles.

Social good is generally an action or application that benefits society. In the past, governments and nonprofit organizations usually drove it. With the advancement of social media via computer-mediated technologies like WeChat, WhatsApp, Weibo, Twitter, Instagram, Facebook, and YouTube, billions of registered users utilize social interactions through social media. As a result, everyone can contribute to society easily and achieve social good.

Tremendous growth of digital information (from granular data to aggregated data) is available for numerous social sciences and social impact applications, for instance, environmental protection, healthcare and education. Data analytics are ubiquitous and purpose-oriented in different forms: descriptive analytics, diagnostic analytics, predictive analytics and prescriptive analytics. Typical challenges for adopting big data technologies for social sciences and social impact are data handling and storage, data quality, computational power of computers and algorithm customization for special 
application and security. More importantly, it seems that our societies have an infinite need for utilizing the value of big data for social impact and thus applications on social good [5-7].

This edited volume aims to consolidate recent advances in big data for social good. Topics of interest for this Special Issue include (but are not limited to):

- Innovative applications of data analytics to social sciences and social impact problems like energy, healthcare, education, food, poverty, injustice, and inequalities in society;

- Machine learning algorithms for big data applications for social sciences and social impact;

- Advanced techniques for handling unstructured, unlabeled and/or missing data;

- Data quality control of big data for social good;

- Big data research-driven policy-making for social impact;

- Standardization for big data infrastructure and framework;

- Big data implications for society;

- Big-data-driven KPIs research for international benchmarking;

- Socially inclusive economic development and growth through big data applications;

- Human-centric big data research;

- Ethical issues on social research of big data.

The final selection of papers includes 19 research studies organized in three sections:

1.1. Section A: Big Data for Social Impact

- Lytras, M.D.; Visvizi, A. Big Data and Their Social Impact: Preliminary Study. Sustainability 2019, 11, 5067.

- Arnaboldi, M. The Missing Variable in Big Data for Social Sciences: The Decision-Maker. Sustainability 2018, 10, 3415.

- Calzada, I. (Smart) Citizens from Data Providers to Decision-Makers? The Case Study of Barcelona. Sustainability 2018, 10, 3252.

- Zhao, J.; Wang, J.; Fang, S.; Jin, P. Towards Sustainable Development of Online Communities in the Big Data Era: A Study of the Causes and Possible Consequence of Voting on User Reviews. Sustainability 2018, 10, 3156.

- Carrera, B.; Jung, J.-Y. SentiFlow: An Information Diffusion Process Discovery Based on Topic and Sentiment from Online Social Networks. Sustainability 2018, 10, 2731.

- Yau, Y.; Lau, W.K. Big Data Approach as an Institutional Innovation to Tackle Hong Kong's Illegal Subdivided Unit Problem. Sustainability 2018, 10, 2709.

1.2. Section B: Techniques and Methods for Big Data Driven Research for Social Sciences and Social Impact

- Păvăloaia, V.-D.; Teodor, E.-M.; Fotache, D.; Danileț, M. Opinion Mining on Social Media Data: Sentiment Analysis of User Preferences. Sustainability 2019, 11, 4459.

- Zhao, Y.; Zhang, G.; Lin, T.; Liu, X.; Liu, J.; Lin, M.; Ye, H.; Kong, L. Towards Sustainable Urban Communities: A Composite Spatial Accessibility Assessment for Residential Suitability Based on Network Big Data. Sustainability 2018, 10, 4767.

- Marine-Roig, E. Destination Image Analytics Through Traveller-Generated Content. Sustainability 2019, 11, 3392.

- Muhammad, R.; Zhao, Y.; Liu, F. Spatiotemporal Analysis to Observe Gender Based Check-In Behavior by Using Social Media Big Data: A Case Study of Guangzhou, China. Sustainability 2019, 11, 2822.

- Lyu, X.; Jiang, C.; Ding, Y.; Wang, Z.; Liu, Y. Sales Prediction by Integrating the Heat and Sentiments of Product Dimensions. Sustainability 2019, 11, 913.

- Blazquez, D.; Domenech, J.; Garcia-Alvarez-Coque, J.-M. Assessing Technology Platforms for Sustainability with Web Data Mining Techniques. Sustainability 2018, 10, 4497. 
- Yoon, S.-W.; Chung, S.W. Semantic Network Analysis of Legacy News Media Perception in South Korea: The Case of PyeongChang 2018. Sustainability 2018, 10, 4027.

\subsection{Section C: Big Data Research Strategies}

- $\quad$ Maer-Matei, M.M.; Mocanu, C.; Zamfir, A.-M.; Georgescu, T.M. Skill Needs for Early Career Researchers-A Text Mining Approach. Sustainability 2019, 11, 2789.

- Park, I.; Yoon, B. Identifying Promising Research Frontiers of Pattern Recognition through Bibliometric Analysis. Sustainability 2018, 10, 4055.

- Olszak, C.M.; Mach-Król, M. A Conceptual Framework for Assessing an Organization's Readiness to Adopt Big Data. Sustainability 2018, 10, 3734.

- Buenaño-Fernández, D.; Gil, D.; Luján-Mora, S. Application of Machine Learning in Predicting Performance for Computer Engineering Students: A Case Study. Sustainability 2019, 11, 2833.

- Kim, E.-G.; Chun, S.-H. Analyzing Online Car Reviews Using Text Mining. Sustainability 2019, 11, 1611.

- Ree, J.J.; Jeong, C.; Park, H.; Kim, K. Context-Problem Network and Quantitative Method of Patent Analysis: A Case Study of Wireless Energy Transmission Technology. Sustainability 2019, 11, 1484.

\section{Conclusions-The Value Added of this Special Issue}

This collection of papers provides an integrative discussion on key issues and challenges related to the adoption of big data research and their social impact. Below we provide a list of the key findings and ideas communicated in this Special Issue:

- The key understanding of big data and their social impact requires sophisticated studies for the measurement of value and the associated perception from individuals and groups. It also requires a sophisticated approach for the linkage of social value to key social challenges and problems. In this context, various key performance indicators have to be justified. A number of individual concerns related to data privacy and anonymity are also important to be addressed.

- The promotion of big data research for social impact still emphasizes the role of the missing variable in big data for social sciences: the decision-maker. The sophisticated analysis of social-sensitive data requires decision makers with the capability to analyze and to link these data with significant social problems. Without this human-centric approach in decision, making any effort for social impact will be of limited contribution.

- The evolution of big data research for social impact requires strategic efforts and initiatives towards sustainable development of online communities in the big data era. These communities will adopt rules and will promote the required culture for linking advanced research based on big data and analytics for addressing significant societal problems with actions.

- Social evolution of big data research is also related to sophisticated data processing methods like analysis of sentiment from online social networks.

- Big data research can justify also a new era for the evolution of social innovation. The exploitation of skills and capabilities beyond local boundaries will link social local capabilities to global social challenges.

- Advanced data mining and analytics approaches are required for the revelation of hidden insights regarding big data linked to social problems. In this direction, many more things have to be done. In the current era, limited isolated approaches prove the capacity of these techniques to deal with social issues. At the other extreme, some rules and ethical norms have to applied in initiatives like social rating systems that violate privacy and personal human rights.

- Sustainability concerns are significant in the context of the social impact of big data research. The perception of big data as social good that must promote social value is a basic axiomatic sentence, but there are many grey areas for the provision of this value as a transparent good in the benefit of the global society. 
We are pleased to be able to present this collection of papers to the research community. The promotion of socially sensitive research especially that that addresses topics related to the use of technology will be a trend in the years to come $[8,9]$. The understanding that social impact and social value are the key objective of any technology-driven innovation is the basic step towards sustainable and socially inclusive growth and development.

Author Contributions: All authors contributed evenly to this Editorial. All authors have read and agreed to the published version of the manuscript.

Conflicts of Interest: The authors declare no conflict of interest.

\section{References}

1. Lytras, M.D.; Raghavan, V.; Damiani, E. Big data and data analytics research: From metaphors to value space for collective wisdom in human decision making and smart machines. Int. J. Semant. Web Inf. Syst. 2017, 13, 1-10. [CrossRef]

2. Lytras, M.D.; Mathkour, H.I.; Abdalla, H.; Al-Halabi, W.; Yanez-Marquez, C.; Siqueira, S.W.M. Enabling technologies and business infrastructures for next generation social media: Big data, cloud computing, internet of things and virtual reality. J. Univers. Comput. Sci. 2015, 21, 1379-1384.

3. Lytras, M.D.; Mathkour, H.I.; Abdalla, H.; Al-Halabi, W.; Yanez-Marquez, C.; Siqueira, S.W.M. An emergingSocial and emerging computing enabled philosophical paradigm for collaborative learning systems: Toward high effective next generation learning systems for the knowledge society. Comput. Hum. Behav. 2015, 5, 557-561. [CrossRef]

4. Visvizi, A.; Lytras, M.D. Rescaling and refocusing smart cities research: From mega cities to smart villages. J. Sci. Technol. Policy Mak. 2018. [CrossRef]

5. Lytras, M.D.; Aljohani, N.R.; Hussain, A.; Luo, J.; Zhang, X.Z. Cognitive Computing Track Chairs' Welcome \& Organization. In Proceedings of the Companion of the Web Conference, Lyon, France, 23-27 April 2018.

6. Visvizi, A.; Mazzucelli, C.; Lytras, M. Irregular migratory flows: Towards an ICT' enabled integrated framework for resilient urban systems. J. Sci. Technol. Policy Manag. 2017, 8, 227-242. [CrossRef]

7. Crusoe, J.; Ahlin, K. Users' activities for using open government data-A process framework. Transform. Gov. People Process Policy 2019, 13, 213-236. [CrossRef]

8. Visvizi, A.; Lytras, M.D. Politics and Technology in the Post-Truth Era; Emerald Publishing: Bingley, UK, 2019; ISBN 9781787569843.

9. Visvizi, A.; Daniela, L. Technology-Enhanced Learning and the Pursuit of Sustainability. Sustainability 2019, 11, 4022. [CrossRef]

(C) 2019 by the authors. Licensee MDPI, Basel, Switzerland. This article is an open access article distributed under the terms and conditions of the Creative Commons Attribution (CC BY) license (http://creativecommons.org/licenses/by/4.0/). 